() Open Access Full Text Article

\title{
Sequential comparison of tiotropium to high-dose ipratropium in patients with chronic obstructive pulmonary disease in a practice setting
}

This article was published in the following Dove Press journal:

International Journal of COPD

12 October 2009

Number of times this article has been viewed

\section{Umair Gauhar \\ Mark Dransfield \\ J Allen D Cooper}

Pulmonary Section, Birmingham Veterans Affairs Medical Center and Division of Allergy, Pulmonary and Critical Medicine University of Alabama at Birmingham, AL, USA
Correspondence: ] Allen D Cooper Pulmonary Division/422 THT, 1900 University Blvd,

Birmingham, AL 35294, USA

Tel + I 205-934- 1339

$\mathrm{Fax}+\mathrm{I}$ 205-558-4765

Email allenc@uab.edu
Objective: To determine the effect of changing anticholinergic therapy in patients with COPD from ipratropium to tiotropium on pulmonary function.

Methods: We examined records of patients prescribed high-dose ipratropium, who were subsequently converted to tiotropium. Spirometric values were obtained within 2 days of the change in medication and after 56 to 224 days of the switch to tiotropium.

Results: 15 subjects were documented to have filled a prescription for ipratropium-containing medications the month prior to the change. Medication compliance over the 6 months prior to the switch in these patients was $72 \% \pm 31 \%$ (mean \pm SD) for ipratropium compared to $87 \% \pm 14 \%$ for tiotropium over the 6-month period after the switch $(P=0.1)$. FEV improved from $1.12 \pm 0.39 \mathrm{~L}$ at baseline to $1.37 \pm 0.49 \mathrm{~L}$ after the change to tiotropium $(P=0.01)$. FVC also improved from $2.45 \pm 0.73 \mathrm{~L}$ at baseline to $2.72 \pm 0.69 \mathrm{~L}$ after the change $(P=0.04)$. Maximal voluntary ventilation was also increased from $39.67 \pm 10.7 \mathrm{~L} / \mathrm{min}$ to $45.13 \pm 15.8 \mathrm{~L} / \mathrm{min}(P=0.045)$.

Conclusions: We conclude that replacing high-dose ipratropium with tiotropium therapy significantly improves pulmonary function in a clinical setting.

Keywords: ipratropium, tiotropium, COPD, pulmonary function, exacerbation rate

\section{Introduction}

To date only smoking cessation or long-term oxygen therapy in patients with chronic obstructive pulmonary disease (COPD) and resting hypoxemia have been shown to impact mortality in this disorder. ${ }^{1,2}$ However, some pharmacologic therapies impact a number of clinical parameters in patients with COPD. ${ }^{2,3}$ Currently there are 2 available inhaled anticholinergic medications, ipratropium and tiotropium, which improve air flow in patients with COPD. Tiotropium has a prolonged duration of action ( $>24$ hours) compared to ipratropium. ${ }^{3}$ A recent study has suggested tiotropium is cost-effective compared to ipratropium. ${ }^{4}$ Tiotropium has been shown to improve 1) forced expiratory volume in 1 second $\left(\mathrm{FEV}_{1}\right),{ }^{3}$ 2) quality of life, and 3) exercise capacity and dyspnea compared to subjects treated with placebo or ipratropium. ${ }^{5}$ Although these premarketing studies suggested an advantage of tiotropium over ipratropium in treatment of COPD patients there has not been any report of the effects of changing from ipratropium to tiotropium therapy in COPD patients followed in a general clinical setting.

\section{Methods}

\section{Selection of subjects}

Clinical records were reviewed of patients followed in a specialized clinic for COPD at the Birmingham VAMC who were previously treated with a regimen that contained 
high-dose ipratropium. This included use of the combination metered dose inhaler containing ipratropium (21 $\mu \mathrm{g}$ per puff), and albuterol ( $120 \mu \mathrm{g}$ per puff), 2 puffs 4 times a day followed by ipratropium metered dose inhaler (MDI) (18 $\mu \mathrm{g}$ per puff) 4 inhalations 4 times a day. This resulted in a total of $456 \mu \mathrm{g}$ of ipratropium inhaled each day. Patients were subsequently changed to tiotropium $18 \mu \mathrm{g}$ capsule inhaled daily with albuterol MDI when necessary. Records of 24 subjects who had spirometry performed on the day of the change from ipratropium to tiotropium were further examined. Four of these subjects had evidence of a COPD exacerbation on the day of the switch and were not evaluated leaving 20 subjects for further evaluation. When only subjects were included who had refilled the prescription for ipratropium containing medications in the month prior to the switch, to minimize noncompliance as a complicating issue, a total of 15 remained for final evaluation.

\section{Calculation of medication compliance}

The records of prescription refills were examined for each of the 15 subjects and the number of prescription refills of ipratropium over the 6 months prior to, or tiotropium over the 6 months after the switch were determined. The percentage of compliance with the respective medication was calculated by the number of months the medication was refilled in those 6 months. If the subject refilled the medication 6 times (all prescriptions were 1 month supply at a time) compliance was calculated as $100 \%$.

\section{Pulmonary function testing}

Spirometry was performed by American Thoracic Society guidelines. $^{6}$

\section{Statistical analysis}

Differences between means were determined by $\mathrm{T}$ test. A $P$ value less then 0.05 was considered significant.

\section{Results}

\section{Subjects and medication compliance}

Table 1 shows demographics of the 15 subjects in the study. Of the total number of subjects 15 patients had stage III, 2 subjects had stage IV and 4 subjects had stage II COPD as defined by GOLD. ${ }^{7}$ All but 1 of the subjects had quit smoking. The average age for the 14 males and 1 female was 69.53 years. Compliance for anticholinergic use was $72 \% \pm 31 \%$ (mean $\pm \mathrm{SD}$ ) for ipratropium 6 months prior to the switch compared to $87 \% \pm 14 \%$ for tiotropium over the 6 month period after change in medication $(P=0.1)$. All patients were using the combination salmeterol/fluticasone inhaler Advair ${ }^{\circledR}$ during the month prior to the anticholinergic switch and through the entire period of the study.

\section{Pulmonary function testing}

Figure 1 shows individual data for the $\mathrm{FEV}_{1}(\mathrm{~A})$ and $\mathrm{FVC}$ (B) determined in the 15 subjects at baseline and after the change to tiotropium. $\mathrm{FEV}_{1}$ increased by an average of $155 \mathrm{~mL}(12.8 \%)(P=0.01)$. Five of the 15 subjects showed

Table I Characteristics of subjects at baseline

\begin{tabular}{lllllll}
\hline Subject no. & Age & Gender & Smoking status & FEV (\%pred) & FVC (\%pred) & Comorbidities \\
\hline I & 73 & $M$ & Former & 1.1 I (35) & $2(46)$ & PUD, GERD, HL \\
2 & $8 I$ & $M$ & Former & $1.4 I(50)$ & $1.72(40)$ & PUD, A Fib, CAD \\
3 & 67 & $M$ & Former & $0.49(14)$ & $1.4(30)$ & UC, Psoriasis, DM, GERD \\
4 & $7 I$ & $M$ & Former & $1.00(36)$ & $2.28(60)$ & BPH, OSA, CAD \\
5 & 76 & $M$ & Former & $0.87(30)$ & $2.43(60)$ & CAD, Cataracts \\
6 & 67 & $M$ & Former & $0.84(27)$ & $1.53(36)$ & HTN, HL \\
7 & 59 & $M$ & Former & $1.14(32)$ & $2.43(52)$ & HTN, OP, OSA, HT, HL \\
8 & 60 & F & Current & $1.40(56)$ & $1.74(58)$ & Depression, DM, HTN, HL \\
9 & 73 & $M$ & Former & $1.78(54)$ & $4.06(88)$ & DVT, OP, HL, ASCVD \\
10 & 77 & $M$ & Former & $0.98(32)$ & $2.3(53)$ & GERD, HTN, Bladder Ca \\
11 & 78 & $M$ & Former & $1.27(44)$ & $3.16(77)$ & HTN \\
12 & 64 & $M$ & Former & $2.07(64)$ & $3.1(7 I)$ & CAD, HL, GERD, Psoriasis \\
13 & 70 & $M$ & Current & $1.53(49)$ & $2.54(59)$ & OP, HTN, GERD, CAD \\
14 & 63 & $M$ & Former & $1.03(3 \mathrm{I})$ & $2.9(65)$ & HTN, BPH, HL \\
15 & 64 & $M$ & Former & $1.26(39)$ & $3.16(73)$ & DM, HTN, HL, GERD \\
\hline
\end{tabular}

Abbreviations: A fib, atrial fibrillation; ASCVD, atherosclerotic cardiovascular disease; BPH, benign prostatic hypertrophy; CAD, coronary artery disease; DM, diabetes mellitus; DVT, deep vein thrombosis; GERD, gastroesophageal reflux disease; HL, hyperlipidemia; HT, hyperthyroidism; HTN, hypertension; OP, osteoporosis; OSA, obstructive sleep apnea; PUD, peptic ulcer disease; UC, ulcerative colitis. 
an improvement of over $200 \mathrm{~mL}$ in $\mathrm{FEV}_{1}$. FVC also improved by an average of $273 \mathrm{~mL}(11.1 \%) P=0.04$. Maximal voluntary ventilation improved $5.46 \mathrm{~L} / \mathrm{min}$, an average of $13.8 \%$ $(P=0.045)$ (data not shown).

\section{Discussion}

Our study suggests replacing high-dose inhaled ipratropium with tiotropium significantly improves FVC and $\mathrm{FEV}_{1}$. The effect on $\mathrm{FEV}_{1}$ suggests tiotropium has an advantage in improving airflow compared to high-dose ipratropium while effects of the change on FVC may be due to lessened air trapping.

A number of premarketing studies suggested tiotropium provides better bronchodilation compared to ipratropium administered 4 times a day and salmetrol administered twice a day, as evidenced by peak $\mathrm{FEV}_{1}$, trough $\mathrm{FEV}_{1}$ and area under the curve. ${ }^{3}$ However, in all of these studies the comparator group was treated with a lower dose of ipratropium then was employed in the current study. Ikeda et al demonstrated that increasing doses of ipratropium up to $240 \mu \mathrm{g}$ had progressively beneficial effects on exercise capacity and $\mathrm{FEV}_{1} \cdot{ }^{8}$ The dose of ipratropium used in our study at each single treatment time was $114 \mu \mathrm{g}$, less than the optimal dose demonstrated in that study but more than comparator ipratropium arms in premarket studies of tiotropium. However, in clinical practice use of a higher dose of ipratropium to achieve a dose of $160 \mu \mathrm{g}$ at each dosing time would be problematic because of the large number of

A

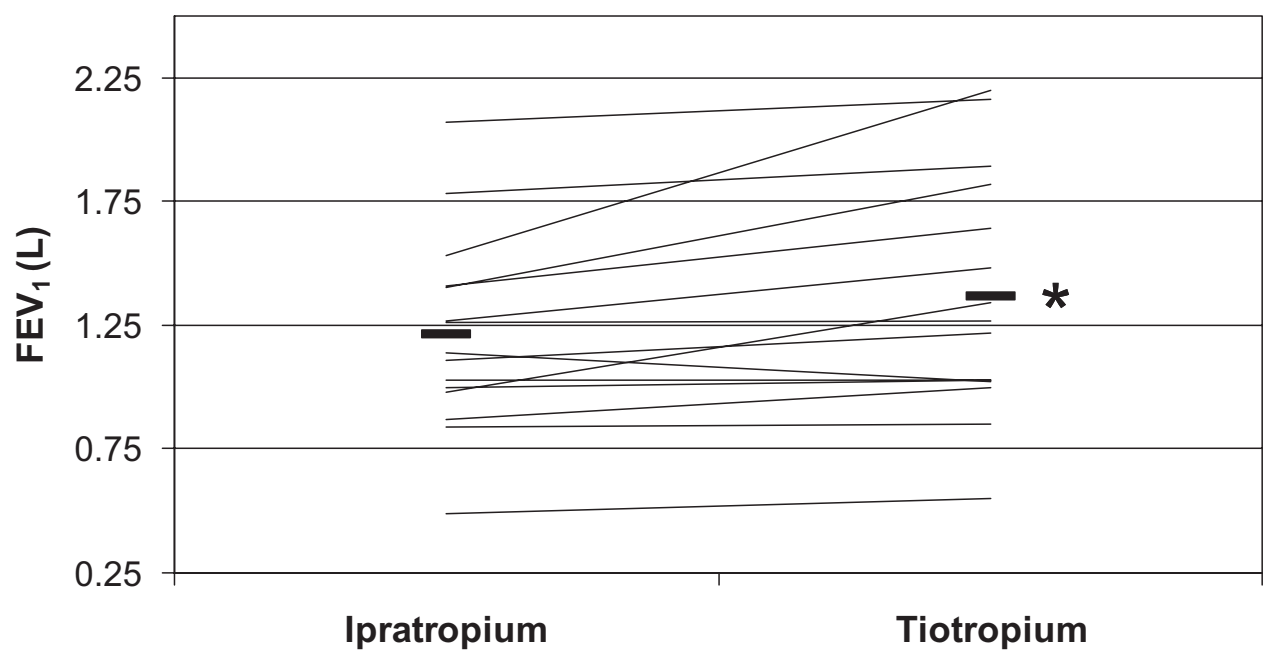

B

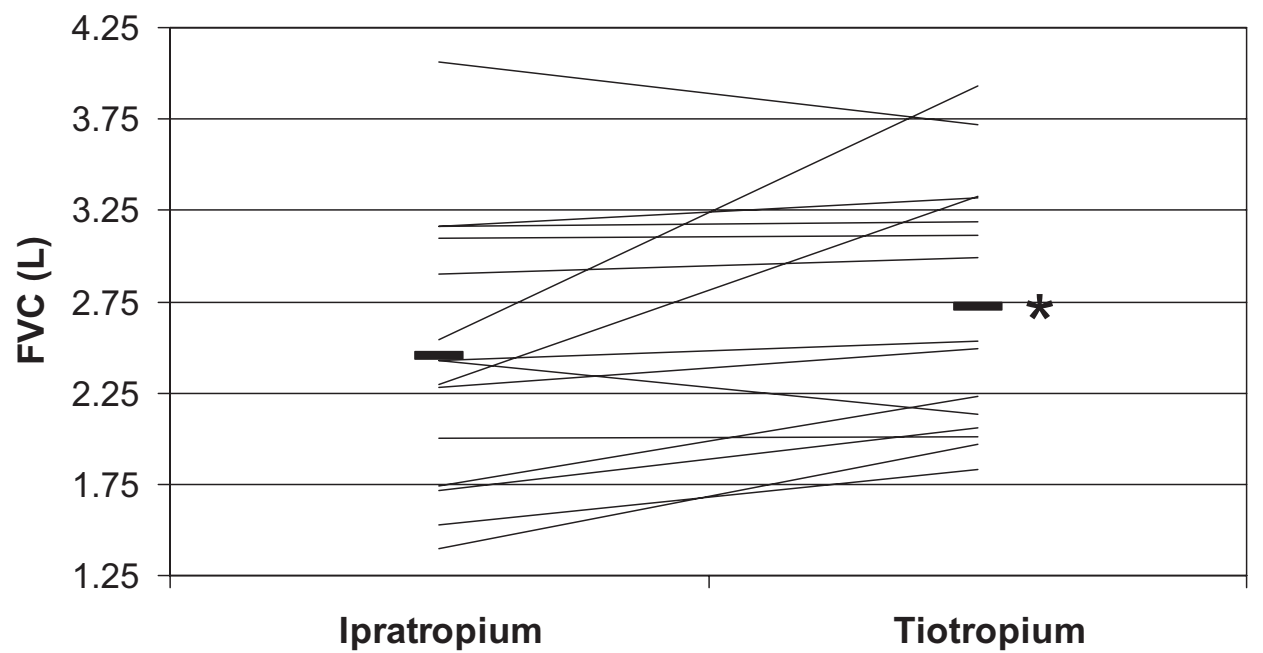

Figure I Effects of the switch from ipratropium anticholinergic therapy to tiotropium on FEV $(\mathbf{A})$ and FVC (B). Note: $* P<0.05$ between the two treatments. 
inhalations required per day and the cost of the number of inhalers required for that dose. To date, several more studies have demonstrated superior improvements in $\mathrm{FEV}_{1}$, FVC and $\mathrm{FEV}_{6}$ with tiotropium compared to placebo, ipratropium and long-acting $\beta_{2}$-agonists. ${ }^{9-13}$ Tiotropium was shown to improve $\mathrm{FEV}_{1}$ regardless of the presence or absence of short-term improvement in $\mathrm{FEV}_{1} \cdot{ }^{14}$ Moreover, improvements in inspiratory capacity and $\mathrm{FEV}_{1}$ with tiotropium in patients with hyperinflation are unrelated to small airway heterogeneity. ${ }^{15}$ Tiotropium has also been shown to reduce dynamic hyperinflation resulting in improved exercise endurance. ${ }^{3,16,17}$

Tiotropium has an excellent safety profile with dry mouth and urinary retention being the only major adverse events. ${ }^{3,13,18-20}$ The incidence of dry mouth was slightly greater than that seen with ipratropium. ${ }^{3}$ However, the effect was mild and did not lead to cessation of therapy. Serious adverse events occurred with the same frequency as in the control group. ${ }^{3}$ A recently published meta-analysis of 17 randomized controlled trials raised concerns about an increased risk of cardiovascular death, myocardial infarction and stroke among COPD patients with use of inhaled anticholinergics (ipratropium or tiotropium). ${ }^{21}$ However, the UPLIFT study did not demonstrate any such risks with long-term use of tiotropium. $^{22}$

Treatment with tiotropium is cost-effective compared to ipratropium. ${ }^{4,23}$ In a retrospective pooled analysis of longacting bronchodilators, treatment with tiotropium was shown to save US\$391 per year while gaining 13 quality-adjusted days compared with ipratropium. ${ }^{23}$ Since hospitalizations due to COPD exacerbations account for up to $70 \%$ of the medical care costs for COPD patients, reduction in hospitalizations is a major reason for cost-effectiveness of treatment with tiotropium. ${ }^{24,25}$

Our study suggests that tiotropium $18 \mu \mathrm{g}$ in a once-daily regimen improves airway flow rates when compared to a previous regimen of $456 \mu \mathrm{g}$ of ipratropium per day. This, and previous studies, suggest an advantage of long-acting anticholinergic agent over short-acting ipratropium. Larger studies may be needed to determine the "real world" physiologic and economic effect of changing from ipratropium to tiotropum as anticholinergic therapy.

\section{Disclosures}

Dr Cooper has been on the speakers' bureau for Boehringer Ingelheim, Pfizer and Glaxo Smith Kline pharmaceuticals in the past and has also performed clinical trials for each of this companies.
Dr Dransfield has been on the speakers' bureau for Boehringer Ingelheim, Pfizer and Glaxo Smith Kline pharmaceuticals and has performed clinical trials for these companies.

\section{References}

1. Sin DD, McAlister FA, Man SFP, Anthonisen NR. Contemporary management of chronic obstructive pulmonary disease. JAMA. 2003;290:2301-2312.

2. Tashkin DP, Cooper CB. The role of long-acting bronchodilators in the management of stable COPD. Chest. 2004;125:249-259.

3. Gross NJ. Tiotropium Bromide. Chest. 2004;126:1946-1953.

4. D'Souza AO, Smith MJ, Miller LA, Kavookjian J. An appraisal of pharmacoeconomic evidence of maintenance therapy for COPD. Chest. 2006;129:1693-1708

5. O'Donnell ED, Fluge T, Gerken F, et al. Effects of tiotropium on lung hyperinflation, dyspnea and exercise tolerance in COPD. Eur Respir J. 2004;23:832-840.

6. American Thoracic Society, European Respiratory Society. ATS/ERS task force: Standardization of lung function testing. Eur Resp J. 2005;26:153-161.

7. Pauwels RA, Buist AS, Calverley PMA, et al. Global strategy for the diagnosis, management and prevention of chronic obstructive pulmonary disease. NHLBI/WHO initiative for chronic obstructive lung disease (GOLD) workshop summary. Am J Respir Crit Care Med. 2001;163:1256-1276.

8. Ikeda A, Nishimura K, Koyama H, Tsukino M, Mishima M, Izumi T. Dose response study of ipratropium bromide aerosol on maximum exercise performance in stable patients with chronic obstructive pulmonary disease. Thorax. 1996;51:48-53.

9. Hsu JY, Perng RP, Lu JY, et al. Double-blind randomized parallel group study comparing the efficacy and safety of tiotropium and ipratropium in the treatment of COPD patients in Taiwan. J Formos Med Assoc. 2006; 105:708-714.

10. Chank CK, Maltais F, Sigouin C, et al. A randomized controlled trial to assess the efficacy of tiotropium in Canadian patients with chronic pulmonary disease. Can Respir J. 2007;14:465-472.

11. Criner GJ, Sharafkhaneh A, Player R, et al. Efficacy of tiotropium inhalation powder in African-American patients with chronic obstructive pulmonary disease. COPD. 2008;5:35-41.

12. Voshaar T, Lapidus R, Maleki-Yazdi R, et al. A randomized study of tiotropium Respimat Soft mist inhaler vs ipratropium pMDI in COPD. Respir Med. 2008;102:32-41.

13. Barr RG, Bourbeau J, Camargo CA. Tiotropium for stable chronic obstructive pulmonary disease. Cochrane Database Syt Rev. 2005, Issue 2. Art No.: CD002876. DOI: 10.1002/14651858. CD002876.pub2.

14. Tashkin D, Kesten S. Long-term treatment benefits with tiotropium in COPD patients with and without short-term bronchodilator responses. Chest. 2003;123:1441-1449.

15. Verbanck S, Schuermans D, Vincken W. Small airways ventilation heterogeneity and hyperinflation in COPD: response to tiotropium bromide. Int J Chron Obstruct Pulmon Dis. 2007;2:625-634.

16. Casaburi R, Kukafka D, Cooper CB, et al. Improvement in exercise tolerance with the combination of tiotropium and pulmonary rehabilitation in patients with COPD. Chest. 2005;127:809-817.

17. Maltais F, Hamilton A, Marciniuk D, et al. Improvements in symptom-limited exercise performance over $8 \mathrm{~h}$ with once-daily tiotropium in patients with COPD. Chest. 2005;128:1168-1178.

18. Barr RG, Bourbeau J, Camargo CA, et al. Tiotropium for stable chronic obstructive pulmonary disease: a meta-analysis. Thorax. 2006;61:852-862.

19. Casaburi R, Briggs Jr DD, Donhue JF, et al. The spirometric efficacy of once-daily dosing with tiotropium in stable COPD: A 13-week multicenter trial. Chest. 2000;118:1294-1302. 
20. Kesten Steven, Michele Jar, Wentworth C, et al. Pooled clinical trial analysis of tiotropium safety. Chest. 2006;130:1695-1703.

21. Singh S, Loke YK, Furberg CD. Inhaled anticholinergics and risk of major adverse cardiovascular events in patients with chronic obstructive pulmonary disease: A systematic review and meta-analysis. JAMA 2008;300:1439-1450

22. Tashkin DP, Celli B, Senn S, et al. A 4-year trial of tiotropium in chronic obstructive pulmonary disease. N Engl J Med. 2008;359:1543-1554.
23. Oba Y. Cost-effectiveness of long-acting bronchodilators for chronic obstructive pulmonary disease. Mayo Clin Proc. 2007;82:575-582.

24. Niewoehner DE. The impact of severe exacerbations on quality of life and the clinical course of chronic obstructive pulmonary disease. Am J Med. 2006;119:38-45.

25. Rice KL, Kunisaki KM, Niewoehner DE. Role of tiotropium in the treatment of COPD. Int J Chron Obstruct Pulmon Dis. 2007; 2:95-105.

International Journal of COPD

\section{Publish your work in this journal}

The International Journal of COPD is an international, peer-reviewed journal of therapeutics and pharmacology focusing on concise rapid reporting of clinical studies and reviews in COPD. Special focus is given to the pathophysiological processes underlying the disease, intervention programs, patient focused education, and self management protocols.

\section{Dovepress}

This journal is indexed on PubMed Central, MedLine and CAS. The manuscript management system is completely online and includes a very quick and fair peer-review system, which is all easy to use. Visit http://www.dovepress.com/testimonials.php to read real quotes from published authors.

Submit your manuscript here: http://www.dovepress.com/international-journal-of-copd-journal 